\title{
Kleine diagnostische Tausendsassas
}

— Der berühmte englische Pädiater und Präsident des Royal College of Physicians, Sir Robert Hutchison (1871-1960), war nicht nur ein begnadeter Kliniker, er verstand sich auch darauf, mit markanten Formulierungen bei seinen Schülern bleibenden Eindruck zu hinterlassen. Berühmt ist sein Zitat über die Urindiagnostik: „Die Geister verstorbener Patienten, die uns in den Träumen verfolgen, fragen nicht, warum sie nicht in den Genuss des letzten Schreis der modernen Medizin kamen; vielmehr fragen sie: Warum hast du meinen Urin nicht untersucht?." Dabei stammt dieses Zitat aus Zeiten, als die chemische Urindiagnostik noch wesentlich aufwendiger war als heute. Die moderne Medizin verfügt dagegen über Urinteststreifen, die zwar simpel aussehen, in denen aber ein biochemischer Mikrokosmos steckt, über den sich die meisten kaum Gedanken machen. Tatsächlich gehört die Harndiagnostik mit dem Teststreifen zu den Untersuchungen mit dem günstigsten Verhältnis zwischen Aufwand und Nutzen.

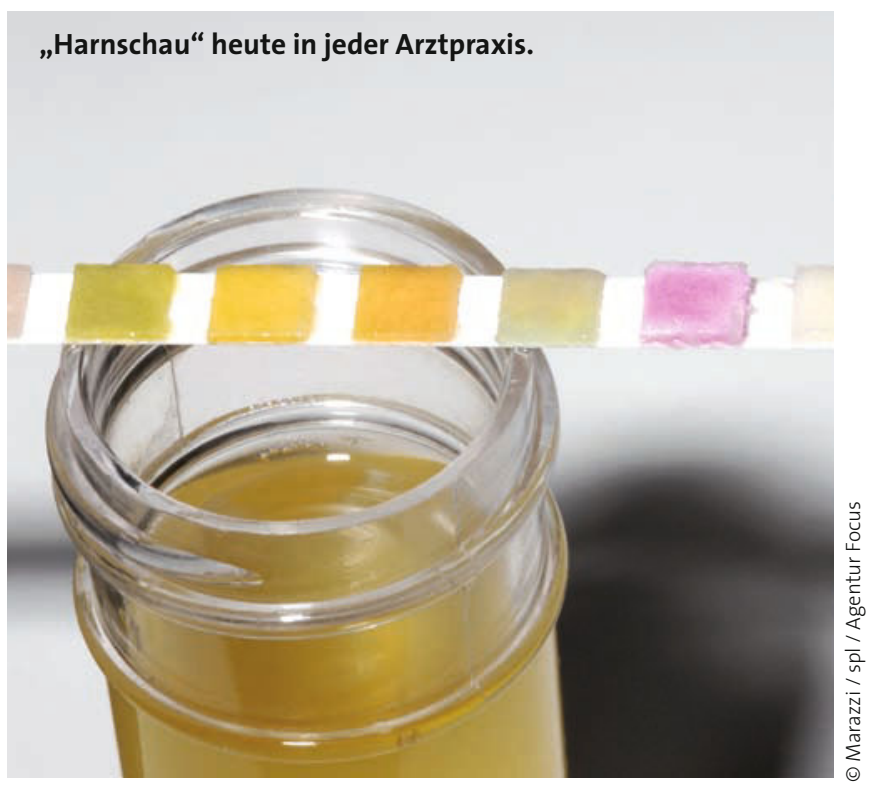

Die etablierten zehn physikalischen, chemischen und zellulären Parameter des Teststreifens lassen nicht nur wichtige Rückschlüsse auf glomeruläre Nierenerkrankungen, sondern auch auf metabolische Störungen, Leberund Gallenwegserkrankungen sowie Infektionen und Tumoren der ableitenden Harnwege zu. Dennoch kann man selbst in Kliniken immer wieder erleben, dass bei Patienten nach einer Woche Aufenthalt zwar eine Fülle

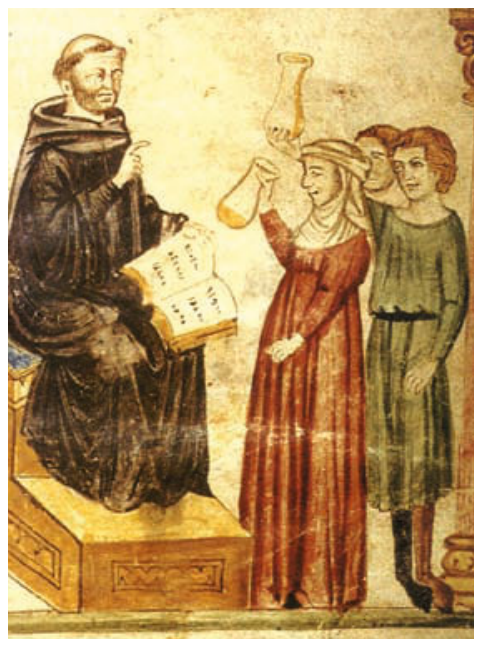

Harnschau im 11. Jahrhundert durch Konstantin den Afrikaner. von serologischen und bildgebenden Methoden eingesetzt wurde, ein Harnstatus aber noch nicht vorliegt. Vielleicht liegt es schlicht daran, dass der Umgang mit dieser Flüssigkeit beim Personal mit weit mehr Vorbehalten verbunden ist als der mit Blut. Leider steht es auch mit der Präanalytik bei diesem Medium nicht zum Besten. Über die Details der Uringewinnung, die Abnahmemodalitäten und die Probleme mit Verunreinigungen bestehen bei Ärzten und Pflegepersonal vielfach Wissenslücken. Daraus resultieren gelegentlich Befundkonstellationen, die zu Sorge und Verunsicherung Anlass geben, bei entsprechenden Kenntnissen aber leicht aus der Welt geschafft werden könnten.

Zu den Urinbefunden mit der umfangreichsten Differenzialdiagnose und hohem Fehlerpotenzial bei gleichzeitig großem potenziellem Krankheitswert zählt die Proteinurie. Der entsprechende Beitrag in diesem Heft soll Ihre Kenntnisse der Urindiagnostik auffrischen und dazu beitragen, dass die warnende Sentenz von Sir Robert Hutchison für die von Ihnen betreuten Patienten nicht zutrifft. Sie legen doch sicher auch Wert auf ungestörten Schlaf und nur gute Träume. 